\section{ENTRE LA PANTALLA Y EL LIBRO: GABRIEL GARCÍA MÁRQUEZ Y EL CINE}

\author{
Robin Fiddian \\ Universidad de Oxford
}

\section{BETWEEN THE SCREEN AND THE BOOK: GABRIEL GARCÍA MÁRQUEZ AND FILM}

\begin{abstract}
Garcia Márquez's relations with the cinema find their first expression in a series of film reviews that the author penned for the Colombian daily El Espectador, in the mid-nineteen fifties. There, he shows a particular predilection for Italian Neo-realism, for certain contemporary Italian films about women, and for the BardemBerlanga classic, ¡Bienvenido, Mr Marshall! Analysis of selected film reviews demonstrates surprisingly close connections with creative works by Garcia Márquez, both at the level of narrative and in key areas of ideology and aesthetics.
\end{abstract}

KEY WORDS: Aesthetic theory; truth; humanity; sensitivity to women's issues, lyricism, the fantastic, film direction; influences.

Un componente de la obra de Gabriel García Márquez que ha sido relativamente ignorado por los críticos es una serie de reseñas cinematográficas redactadas para el diario colombiano El Espectador. Publicadas bajo el título general, "El cine en Bogotá. Estrenos de la semana", las reseñas aparecieron en más de sesenta ediciones del diario entre febrero 1954 y junio 1955 y trataron de un total de ciento ochenta películas. El único comentarista que ha mostrado interés en este material es Jacques Gilard, en la introducción del segundo volumen de la Obra periodística de García Márquez, referente a los años 1954-1955, y con fecha de 1982'. Relacionando las reseñas y artículos de García Márquez con los contextos más amplios del periodismo colombiano y de la renqueante industria cinematográfica nacional, Gilard caracterizó los escritos como "empresa de pionero ... un género nuevo en el periodismo nacional" (Gilard, 1982, 33) y alabó la honestidad de la denuncia, hecha por el autor, del subdesarrollo y dependencia cultural del cine colombiano en la década de los cincuenta. En un registro menos polémico (y más afín a la temática de este número de Arbor), Gilard deducía de las reseñas un programa estético que seria válido para las
RESUMEN: El origen de las relaciones entre la obra literaria de García Márquez y el cine se encuentra en una serie de reseñas de películas, que el autor colombiano escribe para el periódico bogotano El Espectador, a mediados de los cincuenta. En las páginas del diario capitalino, da a conocer por primera vez su afición por el neorrealismo italiano, por ciertas películas italianas contemporáneas de tema femenino, y por iBienvenido, Mr. Marshall!, de Luis García Berlanga. Un análisis de algunas reseñas pertinentes revela sorprendentes conexiones entre la obra de García Márquez y media docena de películas, a los niveles de diseño narrativo y valores estéticos comunes.

PALABRAS CLAVE: Teoria estética; verdad; humanidad; sensibilidad femenina; lirismo; lo fantástico; dirección cinematográfica; influencias.

narraciones del autor: "una concepción del cine [que] tiene innegables vínculos con el sentido del relato y la psicología" (Gilard, 1982, 31) en obras tales como El coronel no tiene quien le escriba (publicada en 1958) y en algunas historias escritas entre 1956 y 1959, que se publicarían en la colección Los funerales de la Mamá Grande en 1962. El propósito principal del estudio presente es analizar más detenidamente algunas de esas reseñas escritas en 1954 y 1955, partiendo de la teoría estética que encierran y explorando ciertos puntos de contacto con la obra creativa de García Márquez, tanto contemporánea como posterior. En segundo lugar, me interesa esclarecer una posible teoría del autor acerca de las relaciones entre cine y literatura, que se esboza en sus contribuciones a El Espectador. Mi estudio se limitará a una decena de películas y a tres o cuatro títulos importantes en la obra y carrera del Nobel colombiano. De las películas comentadas, tres pertenecen al neorrealismo italiano de los cuarenta y principios de los cincuenta; otra pertenece a una fecha más reciente en la producción cinematográfica de ese pais; mi última selección es iBienvenido, Mr. Marshall!, de Juan Antonio Bardem y Luis García Berlanga, de 1952. 
Germania, anno zero ("Alemania, año cero") es el tema de una nota breve, de sólo tres párrafos, que se publicó en el número de El Espectador correspondiente al 27 de noviembre de 1954. La reseña difiere de otras escritas por el autor por referirse a una película filmada y estrenada en un momento histórico anterior: Roberto Rossellini filmó Germania, anno zero en 1945 y el público la vio por primera vez dos años más tarde; la proyección en Bogotá en 1954 adquiere todos los visos de "un homenaje al neorrealismo, en su décimo aniversario" (389). La conmemoración inspira sentimientos encontrados en García Márquez, que lamenta la decadencia del cine italiano de los cincuenta a la vez que expresa una profunda admiración por clásicos del neorrealismo tales como Paisá y Germania, anno zero. Para Garcia Márquez, la película que acaba de ver en Bogotá es una "magnífica creación", que no ha perdido ni un ápice de su fuerza original como representación de la lucha por la vida en los espacios públicos de Berlín, recién terminada la segunda guerra mundial. "Con sus innumerables tropiezos técnicos, con su montaje difícil y su fotografía rudimentaria", a García Márquez sigue pareciéndole ejemplar: "tan inteligente y lleno de ese tremendo calor humano que impuso Rossellini a sus maravillosas aventuras de postguerra" (389). De acuerdo con esta apreciación, un criterio fundamental para decidir la calidad de una obra de arte es la inteligencia y la compasión con que documenta la experiencia de los seres humanos en un espacio y un tiempo que se describen sin artificios y con máximo realismo. En el caso de Germania, anno zero, un factor esencial fue la filmación de "una historia verdadera y cruel" en lo que parece ser tiempo real, con un sentido de ritmo apropiado a las condiciones de vida "en una ciudad bombardeada". El episodio, que sigue los pasos inciertos del protagonista mientras deambula por las calles y plazas devastadas de Berlín, "demuestra que el buen cine no tiene que ser nada distinto de la reconstrucción de lo cotidiano, del reflejo fiel de ese montón de cosas minúsculas, en apariencia inútiles pero cargadas de un profundo significado, que hacen los hombres en cualquier hora de la vida". La cuidadosa sincronía entre el ritmo de la narración fílmica y el ritmo de la vida, convierte el episodio en una de "las secuencias más humanas que se han hecho" (390).

Desde el punto de vista de las relaciones entre literatura y cine, es de notar que la verosimilitud de Germania, anno zero logra exactamente la conjunción de "realidades y lirismos" propuesta, en los años cincuenta y sesenta, por el novelista y cuentista español Ignacio Aldecoa (192569) ${ }^{2}$. Aldecoa fue contemporáneo de escritores como Jesús Fernández Santos, Carmen Martín Gaite y Rafael Sánchez Ferlosio, a la vez que de García Márquez y otros novelistas hispanoamericanos viviendo en el otro lado del Atlántico. En España, como en Colombia, el neorrealismo italiano tuvo un fuerte impacto en los primeros años del medio siglo y aportó una nueva estética que cineastas como Juan Antonio Bardem y José Antonio Nieves Conde y escritores como Aldecoa y Sánchez Ferlosio abrazaron como apta para representar una gama de realidades socio-económicas y políticas a la vez que íntimas y personales. Según han explicado Marsha Kinder en Blood Cinema y Barry Jordan en Writing and Politics in Franco's Spain, el neorrealismo contraía todo un programa político y ético que los directores de cine peninsulares supieron aprovechar para socavar la ideología del Estado franquista, que en 1951 llevaba más de una década en el poder ${ }^{3}$. Ignacio Aldecoa, sin ser "de izquierdas" como lo era García Márquez (dentro de otro contexto político, claro está), intuía acertadamente la capacidad retórica y estética de una combinación de "realidades y lirismos" en el arte literario y cinematográfico de la Europa post-bélica, de la que el neorrealismo italiano ofrecía numerosos ejemplos originales y paradigmáticos.

Un ejemplo perfecto es Umberto $D$., de Vittorio De Sica y Cesare Zavattini (1952), que García Márquez describe, en una reseña que se acerca al ditirambo, como "la pieza maestra de la historia del cine" (475) y como "una obra de arte que honra a la especie humana" (476). La grandeza de la película reside en la autenticidad de su contenido narrativo: la historia de Umberto D. (Domenico Ferrari) lidiando con la pobreza sin comprometer su dignidad, "es válida porque es verdadera, es verdadera porque es humana" . El tono moral del discurso de García Márquez llama la atención, primero, por su coincidencia con las declaraciones de toda una serie de escritores premiados por el comité Nobel, entre ellos William Faulkner en $1950^{4}$. A otro nivel, que es de apreciación técnica, el futuro Nobel colombiano se muestra consciente de los principios básicos de la narración fílmica, al distinguir, de acuerdo con los teóricos estructuralistas, entre histoire y discours / historia y discurso en Umberto $D$. "Hay que establecer una profunda diferencia entre la historia de Umberto D. y la manera de contarla" (475), García Márquez asevera, y declara la construccion de la película todo un éxito: "Una historia igual a la vida había que contarla con el mismo método 
que utiliza la vida: dándole a cada minuto, a cada segundo la importancia de un acontecimiento decisivo. De Sica y Zavattini han dividido el drama en espacios infinitesimales, han planteado el tremendo patetismo que hay en el simple acto de acostarse, de volver a casa; en el hecho sencillo, inevitable y trascendental de existir un segundo". La plasticidad de Umberto $D$. en el orden del discurso es lo que asegura "la fidelidad con que se parece a la vida" (476).

Si se yuxtaponen las dos reseñas consideradas aquí con la creación narrativa de García Márquez de mediados y finales de los años cincuenta, se encuentran algunas correspondencias muy estrechas entre su teoría estética y obras tales como El coronel no tiene quien le escriba, empezada en 1956, y algunos relatos, escritos en su mayor parte en 1958, que aparecerían en la colección Los funerales de la Mamá Grande de 1962. La habilidad extraordinaria de García Márquez de traducir la textura del tedio en la vida cotidiana del coronel recuerda la de Rossellini y De Sica y se basa, como la de ellos, en una misma visión moral, esencialmente humanista. En "La siesta del martes", el ritmo y el tono de la narración sirven para contener los elementos de drama y patetismo que son inherentes en la situación de una madre y su hija que viajan en un tren lento e incómodo, aguantando el calor tropical durante horas, para llegar a tiempo a un pueblo lejano y colocar unas flores en la sepultura de Carlos Centeno, muerto de un tiro mientras intentaba entrar en una casa privada para robar, unos días antes. La mujer y la niña son su madre y su hermana y quieren cumplir con un imperativo moral básico e incuestionable, que consiste en honrar el cadáver de Carlos, sean cuales sean los obstáculos e incomodidades que se les pongan por delante. Habida cuenta de los diferentes medios de expresión en la prosa y en el cine, "La siesta del martes" adapta la fórmula de Umberto D., al narrar una historia de valor y dignidad personales con un respeto escrupuloso por la verosimilitud.

Nosotras las mujeres es una película de equipo que reunió a Alida Valli, Isa Miranda, Ingrid Bergman y Anna Magnani, y suscitó de García Márquez una de sus reseñas más sensiblemente feministas. Encabezada por un prólogo "increíblemente bien realizado" (218), Nosotras las mujeres plasma una sensibilidad femenina, con "la sencillez del arte auténtico"; no obstante una actuación poco convincente de Alida Valli, "la intachable realización de cada episodio [de la película]" logra comunicar "el carácter, los senti- mientos y los problemas de las mujeres". En un comentario acerca del episodio protagonizado por Ingrid Bergman, García Márquez destaca la labor de amor y comprensión de Roberto Rossellini, director, en esta ocasión, de su propia mujer. A propósito de Anna Magnani, lo que Ilama la atención es el temperamento de la actriz, que "[lo hace todo] sola, que todo se lo traga, lo maneja y lo domina" (219). Por un lado, García Márquez expresa una admiración ilimitada por el talento profesional de una mujer extraordinaria y dotada de una personalidad arrolladora; por otro, valora la capacidad del arte para ahondar en la sensibilidad femenina y lograr una representación fundada en el entendimiento y la compasión.

Dentro de su propia obra, las cualidades que destacamos se hacen sentir notablemente en la narración "Rosas artificiales", incluida en Los funerales de la Mamá Grande. Los personajes del cuento son todos femeninos y se mueven en el ámbito de la casa y de la familia. El centro de interés es Mina, la más joven de las tres mujeres, que se dedica con su amiga Trinidad a fabricar flores de papel para las celebraciones de la Semana Santa. Con una parsimonia rigurosa, la narración apunta hacia el abandono de Mina por parte de un amante que se va, dejándola embarazada y víctima de una pasión cuyo símbolo son las rosas y cuyo último referente es Jesucristo en el día de Su Pasión. La tragedia personal de Mina se insinúa oblicuamente, y pasa completamente desapercibida por su madre, que da la impresión de tener pocas luces. No así su propia madre, con quien Mina comparte habitación, ni el lector, que responde a pistas y sugerencias hechas por un narrador sumamente discreto y enterado. Si en el mundo de la ficción "Rosas artificiales" remite a escritores como Chéjov y Hemingway, verdaderos maestros en la comprensión y representación de una sensibilidad femenina ${ }^{5}$, en el canon del cine su punto de referencia más claro e inmediato es Nosotras las mujeres junto con otras películas, mayoritariamente italianas, que llamaron la atención de García Márquez en ese momento, precisamente por la agudeza de su tratamiento de temas femeninos.

Un factor básico común a las tres películas comentadas en estas páginas es su adhesión a un patrón realista, o neorrealista, que prevaleció en el cine europeo de los años que siguieron a la segunda guerra mundial. Otra reseña de García Márquez describe un tipo de película muy diferente desde el punto de vista de la clasificación genérica y de los 
fundamentos estéticos. Se trata de Mirácolo a Milano, de Vittorio de Sica, objeto de una de las reseñas más largas escritas por García Márquez y publicada el 24 de abril de 1954.

Mirácolo a Milano despierta la misma admiración en García Márquez que Umberto D., del mismo director. Como esta película, Mirácolo a Milano (1950) es de nuevo una adaptación de una historia de Cesare Zavattini. Sin embargo, se distingue de Umberto $D$. en cuanto a su origen en una historia de corte fantástico. Según García Márquez, "Totó el bueno, la novela de donde ha sido extraído Milagro en Milán, tenía por escenario una ciudad imaginaria, en la cual la fantasía del autor disfrutaba de entera libertad" (173). Y sigue explicando a sus lectores: "El compromiso con el público fue entonces más difícil de cumplir, pues se trataba de humanizar la fantasía, de hacer pasar la fábula por el filtro del crudo realismo italiano, sin que aquélla perdiera su encanto ni perdiera éste su elevada temperatura humana" (173-74). Tal explicación ayuda a entender la presencia, en Mirácolo a Milano, de incidentes tales como el vuelo en masa de "los miserables de las barracas" que montan en sus escobas y sobrevuelan el barrio donde viven, a la vez que una denuncia de la injusticia social que reinaba en la Milán post-bélica, antes de que empezaran las obras de reconstrucción.

La reseña de García Márquez incluye, entre otras cosas, un análisis de la influencia de los cuentos de hadas en Mirácolo a Milano, unas reflexiones sobre la combinación de "lo real y lo fantástico" en la historia que se cuenta en la película, y un juicio acerca del valor humano y artístico de Mirácolo a Milano, que en su conjunto amplian sensiblemente las coordenadas estéticas trazadas hasta aquí. García Márquez ofrece un resumen de Mirácolo a Milano como "todo un cuento de hadas" (174) hecho de "los desperdicios de la literatura fantástica" (175). Una serie de preguntas retóricas identifican varios elementos que asocian la película con esos dos géneros literarios. García Márquez pregunta: "¿Qué diferencia hay entre la paloma de Totó [instrumento que el joven protagonista usa para conceder los deseos de la gente pobre en su comunidad] y la lámpara de Aladino? ... ¿Qué diferencia hay entre los pozos de petróleo [que se descubren debajo de las barracas de los pobres] y los huevos de oro de la fabulosa gallina? ¿Desde cuándo es una novedad que las escobas vuelen?" (174-75). La presencia de tantos "elementos gastados"
(174) no perjudica ni la belleza, ni la entereza del discurso socio-político de la película.

Además de reconocer deudas con lo fantástico en la película de De Sica, Garcia Márquez considera su interacción y fusión con lo que llama "los elementos de la realidad". Es aquí donde reside el principal interés de su interpretación de Mirácolo a Milano. El autor elabora un análisis de cómo funciona lo sobrenatural en la historia de De Sica, que me resulta agudo y que también se perfila como un precedente teórico del estilo realista-mágico que García Márquez cultivará con tanto éxito, posteriormente. Según Garcia Márquez,

La historia de Milagro en Milán es todo un cuento de hadas, sólo que realizado en un ambiente insólito y mezclados de manera genial lo real y lo fantástico, hasta el extremo de que en muchos casos no es posible saber dónde termina lo uno y dónde comienza lo otro. Por ejemplo: el hallazgo de un pozo de petróleo es un acontecimiento enteramente natural. Pero si el petróleo que brota es refinado, gasolina pura, el hallazgo resulta enteramente fantástico, así como la circunstancia de que en lo sucesivo baste con horadar la tierra con el dedo para que brote una fuente de petróleo. Otro ejemplo: la escena de los vagabundos disputándose un rayo de sol, que ha sido considerada como un acontecimiento fantástico, es, sin embargo, enteramente real. $Y$ en cuanto al desdentado anciano comiéndose un pollo, hay que reconocer honorablemente que no se sabe al fin y al cabo si es el más real o el más fantástico de todos. Igual cosa ocurre con el entierro de la señora Lolotta, que es estéticamente un golpe de genialidad (174). En mi opinión este párrafo demuestra un fino entendimiento de cómo "Io insólito" y "lo fantástico" pueden convivir con un "crudo realismo", cuyos parámetros se extienden más allá de la Italia de la postguerra hacia otros emplazamientos de "lo real".

Las diferencias a nivel de género entre Mirácolo a Milano y las otras películas comentadas en la primera parte de este ensayo son notables. Sin embargo, Mirácolo a Milano sintoniza enteramente con el modelo y proyecto estéticos de García Márquez tal como se formularon en términos de verdad, humanidad y "palpitación de vida". Para el escritor colombiano, "Lo extraordinario del cuento de Milagro en Milán no es el cuento mismo.... La fuerza humana que los realizadores ... han logrado comunicar a este puñado de 
pordioseros, la carga de verdad que hay en cada situación por muy disparatada que sea, y ese ambiente de cruda miseria y de sueño increible y esa palpitación de vida que contagia hasta a las estatuas, eso es lo que hace de Milagro en Milán una película extraordinaria, convincente, humana, iluminada constantemente por el soplo de la genialidad" (175).

Esta referencia al "soplo de la genialidad" apunta hacia una filosofía del arte que es de carácter marcadamente romántico e impresionista. Otros escritos de García Márquez demuestran mayor precisión en cuanto al reconocimiento del papel de los distintos elementos que se conjugan en la creación de una obra de arte cinematográfico. Las reseñas sobre El salario del miedo y El hombre del millón expresan algunos artículos de fe, especialmente con respecto al papel del director y los medios de expresión propios del cine. En cuanto a los individuos que hacen una película, García Márquez da por sentada una jerarquía que sitúa al director por encima del guionista, del fotógrafo y de los actores. Así se hace eco de la teoría del "auteur" promulgada en la revista francesa Cahiers de cinéma, por André Bazin y François Truffaut a partir de 1951. Como ilustración, cita el trabajo de Henri-Georges Clouzot en El salario del miedo, que maneja una misma materia prima que Hugo Fregonese en Viento salvaje y sin embargo produce, no "un folletín de aventuras" sino "una obra de arte" (212). La diferencia con Fregonese radica "en el profundo conocimiento que tiene Clouzot de los elementos cinematográficos". La fotografía, las actuaciones y "la astucia del montaje en el rigor del guión" representan valores importantes, pero lo fundamental son "las tremendas exigencias y ... el profundo sentido humano de la dirección" (213).

En El hombre del millón, los objetivos del director incluyen el de realizar una digna adaptación de una obra literaria prestigiosa, lo que aumenta el éxito de la síntesis lograda: "Basada en una novela de Mark Twain, esta película es un formidable acopio de guión, dirección y actuación que conserva toda la gracia y el inteligente y discreto tono satírico del escritor norteamericano. ...Como ejemplo de lo que puede hacer un buen director, El hombre del millón es insustituible. Así como es una obra encantadora, habría podido ser una farsa intolerable de no haberse realizado con tanta dignidad, con tanta inteligencia, y sobre todo, con esa asombrosa utilización de los medios cinematográficos". Es, de hecho, en el ámbito de la adaptación donde se pone a prueba el dominio, por parte de un director $y$ su equipo, de un "idioma cinematográfico" específico e intransferible. La adaptación por Ives Allegret del cuento de Jean-Paul Sartre, "Les orgueilleux", consigue efectos de autenticidad en la recreación de un ambiente por medio de unas "magistrales imágenes" del fotógrafo, Alex Phillips. La forma de narrar es diferente también, así como la manera de actuar de los protagonistas (366). En su reseña de El niño y la niebla, del director mexicano Roberto Gavaldón, García Márquez hace una lista de los fallos más graves cometidos en el intento de adaptar una pieza teatral de Rodolfo Usigli. Éstos incluyen las actuaciones falsas y exageradas de la veterana actriz Dolores del Río y de un actor adolescente anónimo en el papel titular, y la inclusión de unos diálogos "que en la versión fílmica conservan su inconveniente carácter teatral" (124). La colaboración de Gabriel Figueroa, el famoso fotógrafo, a pesar de ser "diligente" no basta para contrarrestar los defectos de unos adaptadores que no parecen tener la menor idea de que "el cine tiene un lenguaje propio e inimprovisable" (125).

Una prueba "[del] soplo de la genialidad" en la creación cinematográfica, de acuerdo con García Márquez, es iBienvenido, Mr. Marshall!, de Luis García Berlanga, película favorita del cinéfilo colombiano y la última seleccionada para consideración aquí. La reseña de García Márquez sobre este clásico del cine español acusa un nivel de admiración sólo comparable a la reacción ante Mirácolo en Milano y Umberto D., de De Sica y Zavattini. A decir verdad, la reseña dista de ser la más inteligente del autor, debido a una prevalencia de información anecdótica sobre la discusión analítica de temas de fondo. La sección de la reseña que tiene más interés para el estudioso es la segunda mitad, que contiene comentarios sucintos de García Márquez acerca de los personajes principales de la historia de iBienvenido, Mr Marshall!, incluyendo el alcalde de Villar del Río, Don Pablo, interpretado por José Isbert, el cura, Don Cosme, y el hidalgo, Don Luis. Consciente de la deuda con una tradición de estereotipos literarios, García Márquez elogia a García Berlanga y a los otros miembros del equipo por haber superado el costumbrismo y haber dotado a los personajes "con la fuerza de la realidad"; de esta manera, "dejaron de ser pintorescas postales para turistas y se convirtieron en seres vivientes" (124). Los comentarios citados no añaden ningún elemento nuevo al esquema de valores estéticos elaborado en nuestro estudio. Sin embargo, en esta ocasión me interesan los comenta- 
rios que el autor no hace en su reseña, tanto como los que sí aparecen en ella, y me siento atraído por ciertos paralelismos con la obra creativa de García Márquez, no constatados por el autor, que otorgan un valor intrigante a la reseña sobre ¡Bienvenido, Mr Marshall! Los paralelismos giran alrededor de un repertorio de personajes, un interés compartido en los sueños y en el inconsciente, y algunos patrones narrativos, que juntos conducen a sorprendentes conclusiones.

En primer lugar, la comunidad de Villar del Río incluye dos beatas conservadoras que representan un tipo moral que abunda en el mundo de García Márquez, desde la señora Rebeca de "El día después del sábado" hasta Fernanda del Carpio en Cien años de soledad. Estas mujeres suelen ser de miras estrechas y mojigatas, y funcionan, en las narraciones del colombiano, como objetos de sátira de valores puritanos. Lo que es más, suelen pertenecer al grupo étnico y cultural de los criollos, cuyo esquema mental García Márquez pone en tela de juicio a lo largo de su obra. Algo parecido sucede con los curas de pueblo, de abolengo hispánico y de carácter excéntrico, que pierden autoridad y prestigio ante personas como la madre de Carlos Centeno en "La siesta del martes" y ante la indiferencia del pueblo de "El día después del sábado". La presentación irónica de Don Cosme y de sus feligresas chismosas en Villar del Río ofrece un claro paralelismo con ese ambiente pueblerino.

El hidalgo, Don Luis, es un miembro destacado de la sociedad de Villar del Río y otro blanco de la intención satírica de la película de Berlanga. La voz en off de Fernando Rey lo describe socarronamente como "Ese hidalgo. Ninguna mancha y ningún dinero"; si nos fijamos en su aspecto físico, se parece a otro célebre hidalgo castellano, don Quijote, en algunas representaciones populares del mismo. La promesa de la visita de "los americanos" a Villar del Río suscita en Don Luis orgullosos recuerdos de la participación heroica de sus antepasados en la colonización de La Isla Española, y recuerdos menos felices de la confiscación de bienes de su familia por "los yanquis" después del desastre de 1898, lo que le convierte en símbolo de la clase criolla. Al mismo tiempo, la voz en off transmite otra descripción, que tiene una relación inesperada pero inequívoca con el mundo de la ficción de García Márquez: Fernando Rey dice que Don Luis "siempre está esperando una carta que nunca llega. Sus antepasados se olvidan de escribirle, por lo visto". Así como el comentario irónico fortalece la presentación satírica de Don Luis, la situación del hidalgo constituye la matriz misma de la futura historia de El coronel no tiene quien le escriba.

Una segunda red de contactos entre la película de García Berlanga y la obra de García Márquez son las secuencias oníricas que penetran en el fuero interno de cuatro de los ciudadanos de Villar del Rio: el cura, el hidalgo, el alcalde y el campesino, Juan. Como han notado algunos $\operatorname{críticos}^{6}$, los sueños de estos personajes traducen una variedad de estados de ánimo, entre ellos la conciencia intranquila de Don Cosme, el miedo de Don Luis al imaginarse capturado por salvajes canibales en una isla del Caribe, y el deseo de prosperidad de Juan. Las secuencias interesan también por la exactitud con que imitan las convenciones de algunos géneros del cine de Hollywood y del realismo proletario soviético. Este detalle cinematográfico pasa desapercibido por García Márquez en su reseña de iBienvenido, Mr. Marshall! Sin embargo, hay una semejanza al nivel ideológico entre el contenido de la pesadilla de Don Luis y algunos cuentos del colombiano, que dan cabida a sueños de terror y emasculación (véase "La otra costilla de la muerte" de 1948, incluida en Ojos de perro azul) y la alucinación que ocurre al final de "La viuda de Montiel", donde no se sabe si el personaje que tiene un encuentro con la Mamá Grande está viva o muerta; de todos modos, el encuentro onírico es síntoma del carácter supersticioso y neurótico de la viuda de Montiel, producto de una familia holgada y dueña de unas actitudes clasistas que la narración no duda en censurar.

Adelantándonos al año 1981, descubrimos un caso análogo en la madre de Santiago Nasar, que no sabrá interpretar un sueño premonitorio de la muerte de su hijo en Crónica de una muerte anunciada. Además de este dato narrativo, la anécdota de la novela contiene un elemento que remite al patrón de frustración de expectativas que estructura la narración de iBienvenido, Mr. Marshall! Lectores y espectadores se acordarán de la actitud casi infantil de los vecinos de Villar del Río esperando la llegada de "los americanos", con banderas y música, delante de un telón de fondo seudo-andaluz. Cuando la delegación entra en el pueblo, los coches oficiales aceleran, cubren a los vecinos de polvo y siguen su camino, despidiéndose por medio de un letrero neo-imperialista, pegado al maletero del último vehículo, que dice sarcásticamente, "Goodbye!" En Crónica de una muerte anunciada García Márquez describe una situación 
idéntica de frustración cuando el obispo, "con su séquito de españoles", pasa frente al pueblo en un buque que "soltó un chorro de vapor a presión ... y dejó ensopados a los que estaban más cerca de la orilla" (31). ¿Quién sabe si García Márquez, al escribir la novela en el umbral de los mil novecientos ochenta, haría una conexión con el anticlímax del final de iBienvenido, Mr. Marshall!?

Si renunciamos a la especulación y nos atenemos a lo que el autor escribió a mediados de mil novecientos cincuenta, parece curioso que su reseña de la película de Luis García Berlanga mencionara tan pocos detalles de una historia que fuera a coincidir con su obra en tantos puntos y en tantas maneras. La explicación más sencilla sería que, en el momento en que García Márquez componía su reseña en 1954, todavía no había empezado a escribir ni El coronel no tiene quien le escriba ni los otros cuentos a los que nos hemos referido. Aun así, en comparación con las otras reseñas comentadas, la poca atención analítica que Garcia Márquez presta a la película de García Berlanga me hace sospechar que practicaba ya una estrategia de negación de influencias, al principio de una fase creativa en que no tardaria en producir algunas de sus narraciones más logradas y más famosas. Si para algunos lectores esta hipótesis peca de excesiva desconfianza, entonces podemos considerar otra, según la que los tipos y los temas expuestos en iBienvenido, Mr. Marshall! le resultarian tan familiares a García Márquez y tan acordes con su cosmovisión que los asimilaría como naturales del todo y como menos dignos de atención que los aspectos a los que sí dedicó algún comentario en los párrafos de su reseña.

Entre las reseñas de cine escritas por García Márquez en 1954 y 1955, la de iBienvenido, Mr. Marshall! destaca primero, por su carácter selectivo y miope, y segundo, por representar un caso poco frecuente de influencia de la pantalla al libro. Haciendo un resumen de toda la serie de reseñas y películas comentadas, descubrimos una gama más amplia, y quizá más convencional, de relaciones en- tre cine y literatura en la obra de García Márquez. Éstas incluyen la adaptación y la comparación y llegan hasta la admiración sin límites, que suele basarse en una simpatía ideológica hacia un director o una película. Un factor igualmente importante es el reconocimiento instintivo, por parte del autor, de unos patrones estéticos compartidos, como son el compromiso con la verdad y la expresión de una sensibilidad que capta y transmite valores profundamente humanos.

Una pista para entender las simpatías ideológicas y estéticas de García Márquez en el período que nos ocupa serían las circunstancias históricas de Europa y de las Américas en los años de reconstrucción de los cuarenta y los primeros síntomas de la Guerra Fría. La admiración por el cine italiano de la inmediata posguerra y el rechazo de Hollywood son consecuentes con una postura anti-imperialista que García Márquez ya había forjado para finales de los años cuarenta. También era dueño de una postura humanista que coincidia, probablemente de forma inconsciente, con la ideología estética de André Bazin, otro gran admirador de Roberto Rossellini, y su discípulo, François Truffaut. Como ya anotamos en un momento anterior de este ensayo, Bazin y Truffaut eran contemporáneos de García Márquez, como lo eran también de Aldecoa y de Sánchez Ferlosio. Truffaut llegó a escribir su propia serie de reseñas, entre las que hay una titulada "Roberto Rossellini prefiere la vida real" (1963), que contiene la siguiente declaración: "En verdad, Rossellini no siente un gusto especial por el cine, ni por las artes en general. Prefiere la vida, prefiere lo humano" (276) (trad. mía).

Creo que Gabriel García Márquez no solamente habría compartido los sentimientos de Truffaut, sino que habría utilizado las mismas palabras: sintomas y muestras de un Zeitgeist que duró hasta principios de los años sesenta y que inspiró a una generación de literatos y cinematógrafos a promover un esquema de valores compartidos a lo largo de más de una década y en dos continentes. 


\section{NOTAS}

1 Véase el volumen de La Obra periodística de García Márquez que lleva el título "Entre cachacos/1"; el prólogo de Gilard ocupa las páginas 7-87. En este artículo, todas las referencias a materia cinematográfica que se incluyen entre paréntesis son a las páginas de este volumen.

2 La frase "realidades y lirismos" forma parte de unas declaraciones hechas por Aldecoa a Luis de Sastre, a la vuelta de los EEUU en la primavera de 1959. La entrevista se publicó en La Estafeta Literaria.

3 Véanse Jordan, Writing and Politics, 101-115 y Kinder, Blood Cinema, 1553.

4 En noviembre de 1950, García Márquez publicó una nota, "Faulkner, Premio Nobel", que acogía con entusiasmo la noticia de la concesión del Premio Nobel de Literatura (de 1949) al autor de Oxford, Mississippi. Firmada "Septimus", la nota se reproduce en Obra periodística, vol. 1, 494-96.

5 He estudiado ciertas correspondencias entre las obras de García Márquez, Chéjov y Hemingway en una guía crítica, Gabriel García Márquez. Los funerales de la Mamá Grande, 102-106.

6 Los análisis más agudos de las secuencias de sueños en la película de Berlanga son de Kathleen Vernon, "Reading Hollywood in/and Spanish Cinema", 38-42, y de Steven Marsh, "Villar del Río revisited", 34-36.

\section{BIBLIOGRAFÍA}

Recibido: 5 de septiembre de 2008 Aceptado: 9 de noviembre de 2008
Fiddian, Robin W. (2006): Gabriel García Márquez. Los funerales de la Mamá Grande, London, Grant \& Cutler.

García Márquez, Gabriel (1981): Crónica de una muerte anunciada, Barcelona, Bruguera.

- (1982): Obra periodística. Recopilación y prólogo de Jacques Gilard, 6 vols, vol. 2. Entre cachacos/1. BarceIona, Bruguera.

Gilard, Jacques: "Prólogo", en Gabriel García Marquez, Obra periodística, vol. 2. Entre cachacos/1, 7-87.

Jordan, Barry (1990): Writing and Politics in Franco's Spain, London \& New York, Routledge.

Kinder, Marsha (1993): Blood Cinema: the Reconstruction of National Identity in Spain, Berkeley \& Los Angeles, University of California Press.

- (1997): Ed. Refiguring Spain. Cinema/Media/Representation, Durham \& London, Duke University Press.

Marsh, Steven (2004): "Villar del Río Revisited: the chronotope of Berlanga's ¡Bienvenido Mr Marshall!", Bulletin of Hispanic Studies 81, 25-41.

Truffaut, François (1994): The Films in My Life, trad. del francés por L. Mayhew, London, Da Capo Press, 273-77.

Vernon, Kathleen (1997): "Reading Hollywood in/and Spanish Cinema: From Trade Wars to Transculturation", en Marsha Kinder, ed., Refiguring Spain. Cinema/Media/Representation, Durham \& London, Duke University Press.

\section{FILMOGRAFÍA}

¡Bienvenido, Mr. Marshall! (Dir. Luis Berlanga, 1953).

Germania, Anno Zero (Dir. Roberto RosseIlini, 1948).

El hombre del millón (The Million Pound Note, Dir. Ronald Neame, 1953). 
Miràcolo a Milano (Dir. Vittorio De Sica, 1951).

El niño y la niebla (Dir. Roberto Gavaldón, 1953).
Nosotras las mujeres (Siamo donne, Dir. Roberto Rossellini, Luchino Visconti, Luigi Zampa y Gianni Franciolini, 1953).
Paisà (Dir. Roberto Rossellini, 1946).

El salario del miedo (Le salaire de la peur, Dir. Henri Georges Clouzot, 1953). Umberto D. (Dir. Vittorio De Sica, 1952). 